Note: This is a pre-copy-editing, author-produced PDF of an article accepted for publication in Addiction Research \& Theory following peer review. The definitive publisher-authenticated version [Hogan DM (2007) The impact of opiate dependence on parenting processes: Contextual, physiological and psychological factors, Addiction Research \& Theory, 15(6), 617-635] is available online at http://www.informaworld.com/smpp/content $\sim \mathrm{db}=\mathrm{all} \sim$ content $=\mathrm{a} 788266578$

\title{
The impact of opiate dependence on parenting processes: Contextual, physiological and psychological factors
}

\author{
Diane M. Hogan \\ Published in Addiction Research \& Theory, 2007, 15(6), 617-635 \\ Copyright: Taylor \& Francis
}

\begin{abstract}
This article explores the processes through which dependence on opiates affects parenting capacity and family processes. The findings are based on in-depth interviews with 100 parents (50 drug-using [opiate dependent] and 50 non-drug using) living in Dublin. Qualitative analyses of semi-structured interviews suggest that opiate dependence has a specific impact on parenting processes and particularly on the physical and emotional availability of parents and on the capacity of parents to provide an emotionally consistent environment. Parenting behaviours were linked, based on parents' perspectives, to elements of the culture surrounding illicit drugs and their supply and acquisition, to drug treatment regimes and to the physiological and psychological effects of drugs. The implications for children's development and well-being, and for support of affected families, are considered.
\end{abstract}

\section{Introduction}

It is now widely recognised that substance misuse by individuals has consequences for the family as a whole, including children. Although attention is increasingly drawn to the ways in which children's caregiving environment is altered by parental substance misuse (Hogan 1998; Hogan 2003; Kroll and Taylor 2003; Velleman and Templeton 2003), and there is a growing literature on the developmental and mental health outcomes for children of drugdependent parents, the literature investigating the impact of drug misuse on parenting remains surprisingly small (Mayes and Truman 2002). Much of the public and media concern about children growing up in the care of drug-dependent parents focusses on the provision of practical or instrumental care, and on issues of child protection, while relatively little attention has been paid to relational aspects of caregiving, such as the impact of parental drug misuse on parent-child relationships and on family processes.

\section{Links between parental drug-misuse and parenting quality}

Research on parenting has identified a number of dimensions which appear to be negatively affected by drug misuse (cf Hogan 1998: McKeganey et al. 2002, for reviews). Several studies point to an elevated risk of neglect for children of drug users (Famularo et al. 1992; Wasserman and Levanthal 1993; Forrester 2000; McKeganey et al. 2002;), giving rise to concerns about risks to children's health and safety (Kroll and Taylor 2003). McKeganey et al. (2002) found that drug-using parents perceived a risk of severe 
disruption to the stability of daily family life through the channelling of household resources towards payment for drugs, and through disruption to routines such as mealtimes and bed times. Such findings should be interpreted with caution, however, since many studies of child neglecting are based on pre-selected samples, especially those who have come to the attention of child welfare authorities, and may not account for explanatory factors other than drug misuse, such as comorbid psychiatric disorders and psychosocial conditions of parenting (Hogan 1998; Mayes and Truman 2002).

Drug misuse has also been linked with aspects of parenting style, such as responsiveness and involvement with children and approaches to discipline. Kandel (1990) found that parenting quality of mothers decreased as drug involvement increased, with mothers' drug use associated with lower levels of supervision, more punitive disciplinary style, and less closeness and positive involvement with children. Bauman and Doherty (1986) found that, in comparison with non-drug users, methadone-maintained mothers behaved in more power-assertive ways towards their children and displayed more commanding, disapproving, provoking behaviours. Findings are not clear-cut, however, and suggest that drug-use status alone may not be a significant predictor of poor parenting. For example, Bernstein et al. (1984) found that mothers' psychological well-being and psychosocial resources were better predictors of the quality of mothers' interactions with their infants than was their drug-use status, while Johnson and Rosen (1990) found that degree of maternal drug use was unrelated to maternal responsiveness. Suchman and Luthar (2000) reported that parental involvement was the only parenting dimension that could be attributed to addiction, while autonomy and limit setting were better explained by contextual factors.

\section{Links between parental drug misuse and child well-being}

Studies of child outcomes have also produced mixed findings, but generally suggest that children whose parents are dependent on illicit substances such as opiates and cocaine are at some risk for social and psychological difficulties. Some studies uncovered no or few differences between children of drug users and comparison groups on a variety of dimensions, including behavioural adjustment (Fanshel 1975), intelligence (Bauman and Levine 1986) and developmental progress (Burns et al. 1996). On the other hand, children of drug users have been found to be more likely than those in control groups to manifest behavioural problems (Bauman and Levine 1986; Wilens et al. 1995; Nunes et al. 1998; Wilson et al. 2004) and difficult temperament (Tarter et al. 1993), and to fare poorly in terms of socially adaptive behaviour (Bauman and Doherty 1986; Kandel 1990; Tarter et al. $\underline{1993}$ ) and peer relationships (Kumpfer and De Marsh 1986). Stanger et al. (1999) reported that children of drug-using parents scored lower than children from a national US sample of non-referred children on a range of measures of social and academic competence, and higher on measures of internalising and externalising emotional/behavioural problems, but their scores were more positive than those of a national sample of children referred for mental health services. Another possible comparison is between children of users of opiates and children of users of alcohol and other addictive substances. Such a comparison might help in specifying whether there are unique effects on parenting for opiate addiction.

A recent UK study has examined the profiles of parents who do or do not have care of their children (Meier et al. 2004). Using a large database from the UK treatment monitoring system, Meier et al. reported that parents who were not living with their children had more signs of problem drug use and adverse social circumstances than parents who were living 
with their children. The authors suggest that the presence of children may prevent addicts from behaving more self-destructively. Those whose children had been taken into care or were living elsewhere were most likely to share equipment, use stimulants regularly, have unsuitable accommodation, live with another user or have been referred for treatment. The authors conclude that, when looking at the high level of problems of drug users whose children live elsewhere, it is not clear whether the children live elsewhere because of parental, problematic behaviour or whether the problematic behaviour has increased or developed because the parents did not have care of their children. If the former, it indicates that the children concerned may have lived for some time in a very unsuitable familial setting. On the other hand, children not living with their parents may be experiencing stress and, in the case of those in care, the other risks associated with living in care.

To date, research has not adequately explored the processes by which child outcomes (neutral and negative and positive) come about, though recently there has been a growth of interest in explaining links between parental drug dependence and the quality of children's nurturing environments (Suchman and Luthar 2000; McKeganey et al. 2002). One obvious avenue for research is to explore how experiences within the family are affected by parental drug misuse, as such studies may help to identify the conditions under which some children of drug users fare relatively well while others fare poorly. Using this approach, some authors described risks to which children of drug users may be exposed through their parents' drug-related lifestyle (Hogan and Higgins 2001b; McKeganey et al. 2002), such as risk of witnessing and having access to illegal drugs and paraphernalia and of exposure to varying levels of criminal behaviour.

In addition to describing such risks, however, a central question that needs to be addressed is whether drug misuse has unique effects on parenting, separable from the effects of associated factors such as low socio-economic status and psychological well-being. McKeganey et al. (2002) point to the interdependence of drug misuse with many contextual factors that frequently co-occur with drug dependence and the consequent difficulty of discerning the unique relationship between drug misuse and parenting capacity. Since much of the research on drug misuse, parenting and child well-being lacks comparison between the parenting practices of drug users and non-drug users, it is difficult to reach conclusions about the extent to which drug-using parents differ from non-drug users, especially those parenting in poverty. The present study aimed to ascertain the ways in which involvement with illicit drugs affects caregiving, drawing on comparisons of experiences of parenting processes described by drug-using parents and non-drug-using parents living in similar socio-economic circumstances.

\section{Methods}

The study explored the relationship between parental opiate dependence and family processes in day-to-day life within families. It investigated the drug-related social experiences of parents of school-aged children, living in two locations in Dublin, in areas of profound social and economic disadvantage and with high incidence of illicit drug use. Opiate-dependent parents were compared with non-opiate dependent parents living in the same general localities and with similar socio-economic family backgrounds. Semistructured questionnaires were administered to drug-using parents in service settings and to non-drug using parents in their homes. Questionnaires focussed on (a) sociodemographic information (SES, family structure and household composition); (b) parental drug history, treatment and nature of parental absences from the home and separation 
from their child and (c) perceived impact of drug misuse on parenting experience and quality.

\section{Approach to data analysis}

Coding categories were identified using interviewees' open-ended responses. Precise definitions for each category were agreed upon by the two omit principle researchers involved in the study, based upon joint readings of the transcripts. Coding was by themes, which were in part determined by the questions in the semi-structured interview schedule and in part by issues which were raised by the study participants. It must be recognised that drug-using parents might chose to conceal information or provide incorrect information due to their heightened sensitivity to the issue of child neglect, based on their fears that their children will be taken into care. There is reason, however, to be confident that the approach used here yielded reliable and useful information. Parents' reports corresponded closely with those of a range of professionals, including teachers, working with parents and/or their children, who also took part in the study but whose views are presented elsewhere (Hogan and Higgins 2001a). In addition, the majority of parents volunteered information freely about their drug-taking behaviour, including violation of treatment programmes, and involvement in drug-related criminal activities, suggesting some level of trust in the researchers.

\section{Sample characteristics}

Drug-using parents (the target group) were approached through statutory and voluntary service providers, including drug treatment agencies and a prison. The selection criteria were that parents viewed themselves as problem opiate users and had a child of primary school age who had been in their care for most of the previous year. One 'focal child' per family was the focus of study; in the drug-using parents group this child was oldest child of primary school age (4-12 years). All parents who met the sampling criteria were approached by agency staff and researchers and asked to participate in the study, until a quota of 50 had been reached (32 mothers and 18 fathers).

A sample of non-drug-using parents (36 mothers and 14 fathers) was created through random sampling of children in schools in the locations in which the target group of families lived. The sample was selected on the basis of key matching variables, which included the socio-economic background of families, age and sex of focal children of drug users, and where possible, sex of the interviewed drug-using parent. Non-drug users were defined as individuals not known to be dependent on opiates or other illicit substances either currently or at any time during the lifetime of the focal children.

All focal children were, for most of the year prior to data collection, in the care and control of the parent interviewed. The mean age of children of drug users was 8.06 years (SD = 2.17 ) and of children of non-drug users, 7.91 years $(S D=2.21)$. A total of 52 boys and 48 girls were represented in the study and an equal number omits of each sex was included in the target and comparison groups, with 26 boys and 24 girls in each group. The average age of drug-using parents was 30.5 years $(S D=5.8)$ and of non-drug users, 35 years (SD $=6.4)$. A total of 68 female and 32 male parents took part. 


\section{Parental drug use}

37 drug-using parents (74\%) were receiving treatment for opiate dependence. Treatment was defined as engagement with services and included use of 'drop-in' facilities for advice and information. Twenty-six were receiving both medication (methadone) and counselling, while 9 were receiving medication only, 1 was receiving counselling only and one was availing only of the drop-in service at a community agency. The average age of first opiate use for parents was approximately 20 years $(S=4.14)$. Since parents were aged 31 years, on average, at the time of interview, this suggests that the average duration of opiate use was 11 years for this sample. There was a good deal of variation, however, in the age of first opiate use, ranging from 12 to 32 years.

All drug-using parents had used an opiate substance in the previous year. Eighty percent of these parents also used non-opiate substances: Detailed in Table I below. Although parents in the non-drug user group had not used opiates during the lifetime of the focal child, a small number said that they had used cannabis and cocaine in the previous year.

Table I. Non-opiate substances used in previous year

\begin{tabular}{lcrcr}
\hline & Drug users & \multicolumn{3}{c}{ Non-drug users } \\
\hline Substance & $\boldsymbol{N}$ & $\%$ & $\boldsymbol{N}$ & $\%$ \\
Cannabis & 34 & 68 & 5 & 10 \\
Cocaine & 29 & 58 & 1 & 2 \\
Ecstasy & 10 & 20 & 0 & 0 \\
LSD & 4 & 8 & 0 & 0 \\
Speed & 10 & 20 & 0 & 0 \\
Tranquilliser & 34 & 68 & 0 & 0 \\
\hline
\end{tabular}

\section{Drug use of partners/other members of household}

33 drug-using parents $(66 \%)$ said that their spouse was a drug user, and of these 28 were opiate users. In 11 cases, drug-using parents who were interviewed were living with a drugusing partner, indicating that $22 \%$ of the children in the sample were living in a household where both adult carers were dependent on opiates. In addition, 13 drug-using parents said that there was another (non-parental) drug user living in the home. It should also be noted that there was a heroin user in more than half of the families in the comparison group (26 families or $52 \%$ ), but none were adults in a parental role or were partners of the interviewed parent. In 17 families (34\%) the drug user was in the immediate family, that is, a sister or brother, while in the remaining 13 families the drug user was a cousin, nephew or brother in law.

\section{Socio-economic status}

Education levels were similarly low for the two groups of parents, with average age of school-leaving identical across the groups, at 14.8 years, as outlined in Table II below. 
Table II. Parents' educational attainment (highest level of education attained), by group.

\begin{tabular}{lcc}
\hline & Non-drug user & Drug user \\
\hline Completed primary level & 9 & 9 \\
Completed some second level & 35 & 30 \\
Completed second level & 6 & 5 \\
Other training & & 6 \\
Average age of school-leaving & $14.8(\mathrm{SD}=1.6)$ & $14.8(\mathrm{SD}=1.7)$ \\
Number of respondents & 50 & 50 \\
\hline
\end{tabular}

In each group the majority (41 families or $82 \%$ ) lived in public sector housing (mainly local authority flats) while the remaining 9 families $(18 \%)$ in each group owned their own accommodation. $84 \%$ of drug users and $54 \%$ of non-drug users were unemployed.

\section{Family structure and living arrangements}

The groups differed somewhat in terms of family structure, which was not a matching variable in the study. Twice as many drug-using parents were single and living alone (32\%), compared with $16 \%$ of non-drug using parents, suggesting that children of drug users were more likely to be raised in a one-parent household. Among those families with two adults living in the home, there were differences between the groups in marital status; of the $58 \%$ of drug users who were living with a partner, $16 \%$ were married, while in the comparison group, of the $78 \%$ living with a partner, $58 \%$ were married.

Children of drug-using parents were more likely than those in the comparison group to have lived outside the family home, most often with relatives. At the time of interview, 14 children $(28 \%)$ of drug users were not living with the parent interviewed, compared with none of the children of non-drug users. Four (8\%) children of drug users had ever been homeless, compared to two children of non-drug users. Three children of drug users and none of the children of non-drug users have ever formally been placed in care outside the home.

\section{Findings}

Drug-using parents were more likely than non-drug-using parents to state that they were dissatisfied with their levels of availability to their children, both in terms of physical presence and emotional responsiveness, and to express dissatisfaction about the stability of the caregiving environment they provided for their children. Three explanatory categories emerged relating drug misuse to these parenting processes; contextual/lifestyle factors, physiological factors and psychological factors. Lifestyle factors include those relating to the acquisition and ingestion of drugs, imprisonment on drugs-related charges, and attendance at treatment facilities and hospitalisation, all of which had implications for parents' availability. Physiological factors concern the impact of intoxication and withdrawal from opiates on parenting and particularly to emotional responsiveness. Finally, psychological factors concern factors such as pre-occupation with drugs and instability of moods and their impact on parenting practices such as discipline and limit-setting.

\section{Contextual factors: Drugs-related lifestyle}

Lifestyle factors mainly affected parenting processes by reducing parental availability, both in terms of short term absences of parents from the home to obtain drugs, their reduced 
availability within the home during periods of drug taking and long term absences connected with imprisonment and drug treatment.

\section{Financing drugs through crime}

The dominant factor identified by drug-using parents as inhibiting their involvement with their children was the need to spend time acquiring money to purchase drugs, and in addition, spending time procuring drugs. The amount of time taken up with these drugrelated activities depended on two factors; first, the extent of drug dependence and therefore drug needs and second, whether they had a drug-using partner. Those using greater amounts of heroin needed greater amounts of money and therefore spent more time engaged in obtaining money. Money for drugs was typically obtained through illegal activities such as shoplifting and other robberies or selling drugs. High levels of involvement with drugs necessarily meant intensive involvement with crime and this meant spending a lot of time away from families, sometimes meaning absences for days at a time, without a predictable return time. This was particularly true for drug-using fathers, whose views will first be addressed.

Fathers believed their immersion in a lifestyle of theft and heroin acquisition reduced the time they spent with their families, as illustrated by the views of one father, interviewed in prison

"Without a doubt it's difficult to be around [the children] ... I wasn't around them as much. You'd be mainly rushing and haggling looking for money. I went on coke for a while, on that I was totally away from them; the more money I got the more drugs l'd take ..."

Furthermore, time spent with children was viewed as a lost opportunity to invest time in crime to make money for drugs. The same father described how being on heroin distracted him from the things he liked to do and felt he should do, as a father:

“... like taking them to the cinema is very difficult. To do this you've got to have heroin money, you've got to give up a day of crime and then you've got to have picture [cinema] money." (10018, father of 8-year-old boy)

There was agreement amongst all drug users, but especially among fathers with drug-using partners, that these activities were enormously time-consuming

"Being a drug addict is a 24-hour job, out robbing all the time, you're out all the time" (10005, father of 7-year-old girl)

This description of the way in which drug dependence and crime 'pulled' parents way from their children was echoed by many drug-using parents, and depicts a spiral of immersion in drug-dependence and its associated activities, which draw time away from involvement with children. For some men, these demands were not restricted to supporting their own dependency but extended to a partner. In general, these demands were typical of the experiences reported by drug-dependent fathers interviewed for the study, but not of the experiences of mothers.

Drugs-related demands upon mothers depended in part on their partnership situation; some mothers were single and independently supported their own drug dependence (often 
through allowing their homes to be used as a venue for using); some were in relationships with non-drug users and found various means of obtaining drugs. Most were in relationships with drug-using men who helped to support their drug needs. When asked whether it made parenting easier that her partner was also a drug user, one mother replied

"It was easier in one way-he did all the work [robbing]" (mother of 4-year-old girl).

These circumstances afforded such women greater opportunity to spend time with their children in comparison to women without a drug-using partner. Such arrangements were typically short-lived, however, as men who engaged in high levels of crime usually became incarcerated and women reverted to supporting their drug needs through other means. Mothers who did not have a partner to obtain heroin on their behalf and were engaged in high levels of crime to support their drug needs had to find a child-minder in the hours that children were out of school

"I didn't have as much time, with looking for money and trying to get gear, it takes 3 to 4 hours ... It made it difficult, you had to go out and rob, rob for your money and your drugs. If you weren't on drugs you wouldn't have to do that. You have to get someone to mind them while you get [the drugs] and then get them outside for using. I didn't have much time for them, for playing or anything." (11024, mother of 7-year-old girl)

Selling drugs provided a means to finance a personal heroin problem for most of the parents, and this activity constrained parental availability to spend time with their children.

"I'd get him a video to distract him, once he wasn't bothering me ... I knew I couldn't go to the park because I had to sell" (11017, mother of 10-year-old boy)

While some parents reported bringing their children along with them when engaged in crimes such as theft and when selling or buying drugs, most said that they did not have their children with them when engaged in these activities.

Not only did involvement in crimes such as theft and selling drugs restrict drug-using parents' availability, it did so on an unpredictable basis, as the heroin market is subject to change with changing supply and changing crime surveillance, and the amount of money needed is therefore changeable. The amount of heroin needed is also changeable, with the individual's drug taking patterns changing over time. Thus, if a parent was involved in theft or other crimes to raise money for heroin, his or her financial situation could change rapidly, from week to week or day to day, as the following quote from a drug-using mother of three children illustrates

"One of the worst things [about heroin use] was going so low, having no food in the fridge. From robbing ... l'd have thousands ... [it'd be] gone in two to three weeks. From having loads to having none and out pawning stuff ..." (11008, mother of 9-year-old boy)

Non-drug-using parents also had interests and demands that detracted from time available to their children, but this occurred on a more planned and predictable basis. In addition, they found it easier to arrange childcare as absences were not connected with illicit and socially censured activities, and were therefore less hidden. 


\section{Imprisonment}

Drug-using parents were more likely than non-drug users to ever have had involvement with the criminal justice system and to have spent time in prison. Almost half of drug-using parents (48\%) had ever been convicted of a crime, compared with $12 \%$ of non-drug users. Almost half of drug users had served a custodial prison sentence (46\%) and 20 of these $(40 \%)$ had ever been separated from their child for more than two nights while incarcerated. By contrast, $10 \%$ of non-drug users had ever served a sentence, and only one parent had been incarcerated for more than two nights in the lifetime of their child. Among drug users, fathers were more likely to have spent time in prison than mothers: $83 \%$ of drug-using fathers had been in prison and $25 \%$ of mothers. In the comparison group all those who had spent time in prison were fathers. The frequency of incarceration episodes and duration of sentences served in prison, were not possible to assess reliably on the basis of parents' reports.

\section{Drug treatment and hospitalisation}

In addition to time spent obtaining and using drugs, drug-using parents spent considerable periods of time attending non-residential services over the course of their drug involvement and treatment (Table III). Children were often left in the care of relatives and friends or were brought along with parents if child-care was not available. In either case, considerable amounts of parents' time tended to be taken up by their involvement in treatment programmes.

Table III. Parents ever absent from home (for more than 2 consecutive nights), by group.

\section{Reasons for separation}

Residential drug detoxification

Hospitalised*

Hospitalised (psychiatric)

Imprisonment

Parents on holiday

$\begin{array}{cc}\text { Drug user } & \text { Non-drug user } \\ 16(32 \%) & \\ 17(34 \%) & 9(18 \%) \\ 3(6 \%) & \\ 23(46 \%) & 5(10 \%) \\ & 17(34 \%)\end{array}$

*Does not include hospitalisations for childbirth

Parents were also questioned about other separations that took them away from the family home for periods of more than two nights (Table III). Drug users were more likely than nondrug users to have spent time away from their children due to ill health, with $34 \%$ of drug users having been hospitalised, compared with $18 \%$ of non-drug users. Although details were not gathered on reasons for hospitals stays, reported levels of drugs-related illness, which were considerably-higher for drug users, may explain the higher frequencies for drug users (Table IV). In addition, 32\% of drug users had spent time in residential detoxification programmes. Six percent of drug users and no non-drug users had spent time in a psychiatric hospital. 
Table IV. Frequencies of drugs-related illnesses among parents, by group.

\section{Illness}

Hepatitis-C

Hepatitis B

HIV or AIDS

Ever over-dosed on illicit drugs

${ }^{*} 36 \%$ on more than one occasion

\section{Drug users Non-drug users}

$44 \%$

$12 \%$

$14 \%$

$32 \%$ *
$4 \%$

$2 \%$

Non-drug-using parents also reported spending time away from their children, but absences were less erratic and unpredictable. For example, 17 (34\%) reported ever having been on holidays while their children were cared for by members of the extended family.

\section{Drug ingestion}

Drug-using parents were also frequently unavailable to their children while present in the home, when taking drugs. Most parents reported that they typically kept children out of rooms where they were injecting heroin, at least when children had reached an age when parents believed they had an understanding of drug use. Among parents with high levels of daily drug use, there were several periods of the day when they were unavailable.

"[The] kids missed out on time. I tried to maintain a normal life, shopping together and visiting the family. It was inside the house that I didn't spend time with them. Bedtime would take two seconds. Getting them ready for bed and story time ... didn't happen. At meal times l'd go back into the bedroom and leave them to eat. Everything changed when I was inside [the flat]. On the outside I maintained a bit of normality, nobody knew for years ... the people selling outside the flat didn't know" (11001, mother of 7-year-old girl)

Parents perceived this lack of availability as negatively affecting relationships with their children

“... [L]ike coming into a room. l'd be kicking her out, she'd say 'I hate you, you're always kicking me out of the room'. Once you've got the gear you don't give a [expletive]" (11023, mother of 4-year-old girl)

In summary, a variety of demands upon drug-using parents, linked to their drug dependence, caused them to be dissatisfied with what they perceived as their low and erratic availability to their children, both in terms of actual absences from the home, and when present within the home. While non-drug using parents also sometimes spent time away from their children, they did so on a more planned basis, and did not perceive their availability to be low or unsatisfactory.

\section{Physiological factors: Intoxication and withdrawal}

Drug-using parents were also more likely than non-drug users to perceive their attentiveness to their children as erratic. Many drug-using parents believed that the physiological effects of drug dependence rendered them unable to respond fully to their children's emotional needs. Two factors appeared to account for these barriers to caring for children; the (intended) physiological effects of different types of drugs and the impact of intoxication with opiates and other drugs on energy levels and wellness. 


\section{Intoxicating effects}

The main parents reported that the intoxicating effects of heroin and other forms of opiates were to induce sleepiness or drowsiness. In addition to the intended calm-inducing effects of heroin, several parents associated heroin use with a more generalised physical tiredness and lack of energy.

"when I was on the gear, you were just drained, no energy, not in humour, it's terrible" (11022, mother of 6-year-old girl)

Indeed many said that their children complained about their tendency to fall asleep during the day and to lack energy to play with them. Few drug-using parents were using only one illicit substance, as illustrated in Table I above. Most were taking mainly opiate substances and cannabis, but 58\% reported having taken cocaine in the previous year. It is not known how frequently those individuals took cocaine, but several parents perceived distinctly different physiological effects of cocaine and opiates, and indeed, of lifestyle. One mother, for example, emphasised that taking cocaine caused her to become extremely chaotic and unable to care for her children in any way.

\section{Withdrawal effects}

Many drug-using parents associated the process of withdrawal from heroin with inability to pay attention to their children and saw the physical feeling of withdrawal symptoms, such as sweating, diarrohea and vomiting, which they described as being 'sick' or 'dying sick' as one of the most serious impediments to engage with children.

"You weren't able to give them attention. Not being able to do stuff was the main problem. As soon as I got something into me I had time for them" (11028, mother of 9-year-old boy)

Other effects of withdrawal included irritability and depression, which will be considered in more detail below in terms of psychological effects.

Depending on the intensity of a parent's use of drugs at any given time, movement through cycles of intoxication and withdrawal could occur several times per day. The intensity of the withdrawal, and therefore of parents' emotional distance from their children, was unpredictable. It was in this sense that some drug-using parents saw themselves as 'chaotic'.

"[Being a drug user] made me totally chaotic, totally unmanageable. In reality I was unable to look after [the children]. I always tried to make time for [my son], if I wasn't sick or in withdrawal l'd devote time to him. But half the time I wouldn't even know he was there. He wouldn't have got the attention he needed" (father of 6-year-old boy)

One sense in which parents' emotional unavailability to their children was predictable, according to most parents, was that withdrawal sickness was worst in the mornings, following a night of abstention. More than one-third of parents $(36 \%)$ spontaneously identified mornings as the most difficult part of the day in terms of withdrawal and its impact on parenting. They believed their children, even when very young, were conscious of changes in their behaviour in the mornings. 
"She knew never to go near me in the morning 'till I had my 'foil [smoke heroin], then Mammy would play ... In the mornings the sickness was the worst ... l'd just be telling her to get away. Once I had the gear l'd be the best mother on the earth" (11023, mother of 4-year-old girl)

Some parents also found looking after their children especially problematic when they were trying to abstain from heroin, and when the physiological effects of withdrawal were severe.

\section{Psychological factors}

This category encompasses such issues as the relative priority given by parents to meeting their drug needs and providing care for their children. In addition, it concerns parents' reports of unstable moods and irritability and anxiety, which were also linked with physiological states and especially to withdrawal.

\section{Pre-occupation with drugs}

Most drug-using parents stated that the effects of withdrawal caused them to place a higher priority on maintaining a regular supply of drugs than of attending to the social and emotional needs of their children. One father, who had a 10-year-old boy, said he ceased to care about others when he was at the height of his dependence on heroin

"you don't care about no one, no matter who they are" (10014, father of 10-yearold boy)

Another father, who had a 6-year-old boy (focal child) and two younger children and who had injected every 2 h, 10 times per day, said

"[They] weren't getting any attention. It was always me, always worrying about where me next turn on was coming from" (10006, father of 6-year-old boy)

The notion of immersion in drug dependence to the extent of ceasing to care about others was echoed in the comments of several parents. For example, one mother described her experience of overwhelming pre-occupation with heroin, to the detriment of her children's well-being

"You just sit down and put needles in your arm, you don't care ... always trying to get money and wondering where you'll get you next hit. Its hard being with them crying in your face and you're sick, you're roaring and shouting at them ... its not fair on the kids." (11004, mother of a 9-year-old girl)

It should be noted that, in evaluating the impact of their drug dependence on their parenting, most drug users distinguished between the physical and emotional needs of their children. Most believed that even when their heroin use was intensive and their own resources low, their children's physical needs were catered for adequately, albeit often by another family member rather than by themselves. Many of these parents readily acknowledged that adequate physical care of children was only made possible by means of extensive social support, mainly from their families, and that it was achieved with some difficulty. Where children are functioning well or doing less badly than might be expected, it may well be due to the protective role of extended family members, typically-in this sampletheir grandmothers. 


\section{Depression and irritability}

Several drug users believed depression to be an outcome of their opiate use, supporting findings of previous omit of work linking opiate use with mood disorders (Rounsaville et al. 1982). Several parents referred to the instability of their emotional sensitivity to their children, which was linked with the instability of their physiological and psychological states. Their own emotional states and openness to their children depended on how recently they had taken drugs

"You only had time for your kids when you were stoned, at other times you couldn't give a [expletive] to be honest. At times it was only false love; she'd be sleeping and you'd be crying beside her ... other times once she was out of the way, you didn't give a [expletive]." (11023, mother of 4-year-old girl)

Similarly, the mother of a 9-year-old girl (focal child) and three other children attributed her depression to the effects of drug dependence, causing her to have insufficient energy to give her children the attention and time she believed they needed:

"The effects were ... not being able to do housework, or cook, always being tired, not bringing them out on a walk, to the pictures, not doing them up the way I used to. When I'm depressed I'm always tired ... I often lay in bed for the day, was always having to go to bed. When you're on drugs you don't smile any more, you're not happy in yourself and your self-esteem is low." (11040, mother of 9year-old girl)

Another effect of withdrawal described by drug users was irritability. When they needed drugs and were feeling sick, pre-occupied and anxious they were more likely to be irritable with their children, and to shout at them, rather than using another method of control. One mother of a 10-year-old boy said 'If I didn't get [heroin] before school I'd be roaring and shouting'. They were most likely to interact with their children in this way in the mornings, before taking heroin for the first time in the day.

A mother with a 9-year-old girl described her reaction to her children's misbehaviour when she was taking heroin, prior to starting methadone, as negative and harsh

"I'd clatter them, when I didn't have drugs I'd roar. I know l'd be real nice to them when I had drugs, I never hit them when I was on drugs. I don't know if I'll ever be able to repay them ... maybe by staying off drugs ..." (1140, mother of 9-yearold girl)

She found that her disciplinary style was tied to her psychological state in different phases of her drug taking throughout the day. She was permissive when she had recently taken heroin and extremely strict and irritable when she needed heroin

"drugs made me more calmer. I let them get away with it. I shouldn't have ... that's what a parent is all about. At times I couldn't wait to get them to school [in the mornings] so they wouldn't get the brunt of me, I was like an antichrist. I'd have to ask [my partner] to get up and get [heroin]." (11040, mother of 9-year-old girl) 
This reflects a general theme of drug-using parents' responses; that their interactions with their children tended to vacillate between negative and positive episodes, which corresponded to how parents felt, physically and psychologically as they moved through the cycle from withdrawal to intoxication and back to withdrawal. Several parents described these shifts as 'mood swings'. In the words of one father

"when you get a turn on you're as nice as pie, when you haven't got it you're like the devil" (10013, father of 8-year-old girl)

Many drug-using parents reflected with remorse on the instability of their parenting behaviours and showed concerns about the implications for their children's development. Several said that they experienced an on-going struggle to compensate their children for the attention they believed they were missing out on. One mother, who had spent most of the previous 2 years in homeless hostels with her children, said that her addiction had taken over her life and that of her children, leaving her emotionally volatile and prone to extreme behavioural change between episodes of drug taking.

"I'd feel guilty ... sometimes I spoil her too much ... at times I found it difficult [to look after her] when I was sick. I'd feel guilty. After using it was easier on them cause I was on a high. When I was down or off drugs I'd feel guilty" (11035, mother of 4-year-old girl)

Some parents felt further guilt about their efforts to compensate their children, as they saw that this in turn brought negative consequences. For example, one parent believed that, instead of setting clear limits on her child's behaviour, she tended to change the rules depending on her need for drugs and her desire to prevent her child from witnessing her drug use, with negative consequences for her child's social development.

"I found myself bribing him a lot. I'd say "go on in and watch TV". If he asked to see an 18's video l'd say "go on and do what you like"... and "I'll give you £2 to buy sweets", all so I could be in the kitchen just so he'd be out for 10 minutes. He'd say "I won't come in if you let me stay up until 12". I was so interested in getting heroin I was giving him the wrong sense of values." (11030, mother of 9year-old boy)

While some non-drug using parents also experienced volatility in parenting style, and especially in relation to limit-setting, no clear systemic relationship emerged that appeared to provide an over-riding contextual explanation for their approach to parenting; rather, their parenting approach could be explained pre-dominantly by their personal experiences of being parented within their own families, some of which had cultural and contextual roots and by personal beliefs and values about child development. While such factors undoubtedly also contributed to the parenting experiences of drug users, the latter made direct connections between their drugs-related lifestyles and the psychological and physiological factors they associated with opiate dependence.

\section{Discussion}

The present study provides explanations about the processes that link parental drug dependence with parenting behaviour. The findings suggest that opiate dependence has a specific impact on parenting processes and particularly on the physical and emotional 
availability of parents and on capacity of parents to provide an emotionally consistent environment.

Drug-using parents were less likely than non-drug users to perceive themselves as being available and emotionally responsive to the children in their care as a result of the lifestyle surrounding their drug dependence. Suchman and Luthar (2000) also found evidence of an association between drug dependence and lack of parental involvement. In the present study, this influence could be traced to elements of the culture surrounding illicit drugs and their supply and acquisition, to treatment regimes and to the physiological and psychological effects of drugs. Drug-using parents also reported having difficulties, traceable to the physiological and psychological effects of drug-dependence, in providing consistent caregiving, especially in terms of emotional responsiveness and limit-setting.

In terms of relational caregiving, most drug-using parents believed that their children had 'lost out', while most non-drug using parents believed their children had positive experiences of parenting, often in spite of adverse socio-economic conditions. Drug users' dependence on opiates, by their accounts, detracted from their availability on a day-to-day basis in most families. The main impediments to parental availability included time spent outside of home obtaining money for drugs (stealing or dealing), acquiring and/or selling drugs. Children of drug users were more likely than children of non-drug users to experience separations from their parents and especially their fathers, due to imprisonment. They were more likely to have parents who were frequently in hospital. Parents' reports suggest that, when their drug use was active, as it was periodically over the time since they had first started using heroin, children were faced continuously with the prospect of separation from a parent. Even when in the care of their parents in their own homes, many children of drug-dependent parents had sporadic access to them, and received unreliable levels and quality of attention. Furthermore, almost all drug-dependent parents saw their active drug use as interfering with the quality of the time they spent with their children, in terms of how attuned they were to their emotional needs, and how much attention they gave them. When their parents were intensively engaged in a lifestyle involving high levels of heroin use and crime, children of drug-using parents were likely to experience chaos in their caregiving environments that mirrored the chaos of their parents' own lives.

Perhaps the most serious implication of parental drug misuse for children was not decreased availability per se, but the implied unpredictability of their access to parents, a factor that was considerably less likely to impinge on the family experiences of children whose parents were non-drug users. It should be noted, however, that most children of drug users represented in this study had parents who were receiving methadone treatment, and whose lives were currently relatively stable in comparison with other periods of their lives. Given the volatility of opiate dependence, however, and the fact that most parents were using illicit substances in addition to taking methadone, it is unlikely that this stability was sustainable in the lives of all of these children.

Drug-dependent parents, both mothers and fathers, generally had low confidence in their ability to provide adequate attention and nurturing to their children during periods of heroin use, although they had few doubts about ensuring that their children's basic needs for food and shelter were met. Their reported feelings of guilt and regret about relational caregiving were in keeping with findings from previous studies (Deren 1986; Taylor 1993). Most were self-critical and appeared to view their drug dependence as personal failure and weakness rather than as a social problem, or to attribute a dual role to personal and contextual 
factors. They tended to attribute sole responsibility to themselves for short-comings in the quality of care they provided for their children. Thus, none of the parents referred to the role that societal negative constructions of heroin users, the criminalisation of heroin or inadequacies in formal support services for families facing their particular difficulties might play in influencing their capacity to meet parental responsibilities.

\section{Reports of mothers and fathers}

The reported effects of drug use on parenting were similar for mothers and fathers, in terms of physiological reactions to dependence on drugs; both experienced reduced ability to 'be there' emotionally for their child when they were intoxicated or in withdrawal. The psychological effects were also similar, in that both men and women reported feelings of guilt and remorse about the impact of their drug dependence on their children. It was in the area of lifestyle that differences between mothers and fathers emerged most clearly; fathers were more likely to be separated from their children both in the course of daily life, since they were absent a great deal, and in terms of lengthy separations, since they were more likely to spend time in prison.

\section{Implications for children's well-being and development}

The psychological consequences for children of low levels of parental involvement, including low or erratic levels of emotional responsiveness, separation from parents and unstable or inconsistent caregiving environments have been well-researched, though not specifically in the context of parental drug misuse. Low levels of involvement by parents who are present in the home, such as minimal supervision and monitoring, has been linked with a range of negative outcomes for children, and especially risk for conduct and emotional problems (Patterson and Stouthamer-Loeber 1984; Simons et al. 1994).

Parental emotional responsiveness has been identified as an important predictor of positive social development. Across childhood, sensitive attunement of parents to children's capabilities and to their developmental tasks seems to promote emotional security, behavioural independence and social competence, as well as intellectual achievement (Demo and Cox 2000). Responsive caregiving has been found to act as a mediator of the effects of adversity on children's well being (Egeland et al. 1993). Low parental emotional responsiveness, on the other hand, has potentially negative implications for children's development and welfare and for the security of attachment relationships (De Wolff and van ljzendoorn 1997). These relationships need to be investigated in the context of parental drug misuse, where the physiological and psychological effects of drug intake and withdrawal, as well as the social context may have particular implications for children's risks and outcomes.

Finally, it has long been recognised that instability and discontinuity of care-giving pose threats to children's emotional well-being. Recent literature suggests that family instability may have a negative impact on children's sense of emotional security in the family and sense of control over their immediate environment (Ackerman et al. 1999). The particular implications for children being reared in the context of parental opiate dependence, which may be chronically relapsing, need investigation. The significance of separations that occur in the context of parental drug use, and its correlates, such as imprisonment, hospitalisation and death of parents due to drug misuse, needs urgent attention from researchers. The impact on parent-child relationships of the enforced separation brought about by parental incarceration, under the constraints of prison visiting policies, which may limit parent-child 
physical contact, and in the context of parental drug use and its associated stigma, is an important avenue for future research.

\section{Implications for support}

The clearest implication arising from this study is that support should be targeted at families as systems, rather than at drug users as individuals. It should focus on ensuring continuity, not only of instrumental caregiving, but also of emotional caregiving to children, particularly through periods of critical transitions associated with the changing lifestyle and patterns of drug use and treatment of their parents when parental ability to sustain positive involvement may be especially low. This research also highlights areas of particular vulnerability in the course of daily life, such as early mornings. Programmes are needed that target these periods and that help reduce risks for children. Such programmes should recognise that opiate dependence may be chronic, with periods of more intense support needs.

Social services need to be alert to the risk that children may be in need of substitute parental care at short notice and/or for unpredictable lengths of time and make suitable arrangements with extended family members or professional carers. Interviews with professionals linked to these families, reported in Hogan and Higgins (2001a), revealed a concern amongst professionals that grandparents were being expected to pick up the pieces very often and that they were often themselves in need of support. Sometimes grandparents were reluctant to let their drug using son or daughter resume their parental role or there was conflict between the parent and the grandparents. Hogan and Higgins conclude that 'family support is often a complex issue that requires greater understanding' (2001a, p 27).

The children in this sample were not receiving any counselling or support which was geared specifically to helping them to deal with their parent's addiction. Such support might be needed in many cases. Also parents who are addicts may need advice and support around their parenting role and the consequences of their addiction for their children. Since some parents and children are coping well most of the time, an open door service might be well suited to the needs of many parents and children. Such a service should be oriented towards the family not just the addict. The need for more intense, individual interventions may be expressed or identified more easily when parents and children have ready access to a family-oriented service, which does not seek to pathologise their behaviour or their experience.

\section{Conclusions}

Parents' reports indicate that drug misuse affects parenting in specific ways, which have a negative impact on parental capacity to be emotionally available and responsive to their children on a stable basis over time. The implications for children's well-being and development need further study. Future research should explore children's subjective experiences of family relationships in the context of parental drug misuse, and especially children's experiences of security and closeness within their families. Support services should be family-oriented and designed to provide long-term support for families, with the capacity to provide increased support during periods of particular vulnerability. 


\section{Acknowledgements}

I am grateful to $\mathrm{Dr}$ Louise Higgins for valuable assistance in data collection and to Professors Sheila Greene and Robbie Gilligan of The Children's Research Centre, Trinity College Dublin, for their support for this study. Particular thanks to Sheila Greene for her substantial help in the final preparation of this article for publication. The study was conducted with the support of funding from Enterprise Ireland under the 'Science and Technology Against Drugs' programme.

\section{References}

- 1. Ackerman, BP, Kogos, J., Youngstrom, E., Schoff, K. and Izard, C. (1999) Family instability and the problem-solving behaviors of children from economically disadvantaged families. Developmental Psychopathology 35 , pp. 258-268.

- 2. Bauman, PS and Doherty, FE (1986) Drug-addicted mothers' parenting and their children's development. The International Journal of the Addictions 18, pp. 291-302.

- 3. Bauman, PS and Levine, SA (1986) The development of children of drug addicts. The International Journal of the Addictions 18 , pp. 291-302.

- 4. Bernstein, V., Jermey, RJ, Hans, SL and Marcus, J. (1984) A longitudinal study of offspring born to methadone-maintained women: II Dyadic interaction and infant behaviour at 4 months. American Journal of Drug and Alcohol Abuse 10, pp. 161193.

- 5. Burns, EC, O'Driscoll, M. and Wason, G. (1996) The health and development of children whose mothers are on methadone maintenance. Child Abuse Review $\mathbf{5}$, pp. 113-122.

- 6. Demo, DH and Cox, M. (2000) Families with young children: A review of research in the 1990s. Journal of Marriage and the Family 62 , pp. 876-895.

- 7. Deren, S. (1986) Children of substance abusers: A review of the literature. Journal of Substance Abuse Treatment 3 , pp. 77-94.

- 8. De Wolff, M. and van ljzendoorn, MH (1997) Sensitivity and attachment: A metaanalysis on parental antecedents of infant attachment. Child Development 68 , pp. 571-591.

- 9. Egeland, B., Carlson, E. and Sroufe, LA (1993) Resilience as process. Development and Psychopathology 5 , pp. 517-528.

- 10. Famularo, R., Kinscherff, R. and Fenton, T. (1992) Parental substance abuse and the nature of child maltreatment. Child Abuse and Neglect 16 , pp. 475-483.

- 11. Fanshel, D. (1975) Parental failure and consequences for children: The drugabusing mother whose children are in foster care. American Journal of Diseases in Children 65 , pp. 604-612.

- 12. Forrester, D. (2000) Parental substance misuse and child protection in a British sample. Child Abuse Review 9 , pp. 235-246.

- 13. Hogan, DM (2003) Parenting beliefs and practices of opiate-addicted parents: Concealment and taboo. European Addiction Research 9 , pp. 113-119.

- 14. Hogan, D. (1998) Annotation: The psychological development and welfare of children of opiate and cocaine users: Review and research needs. Journal of Child Psychology and Psychiatry 39 , pp. 609-620. 
- 15. Hogan, D. and Higgins, L. (2001a) When parents use drugs: Key findings from a study of children in the care of drug-using parents The Children's Research Centre, Trinity College, Dublin

- 16. Hogan, DM and Higgins, L. Cleary, A., Phadraig, M Nic Ghiolla and Quinn, S. (eds) (2001b) Children. Understanding children, Vol. 1, Changing experiences and family forms pp. 119-143. Oaktree Press, Dublin

- 17. Johnson, HL, Glassman, KB, Fiks, K. and Rosen, TS (1989) Resilient children: Individual differences in developmental outcome of children born to drug abusers. The Journal of Genetic Psychology 151 , pp. 523-539.

- 18. Kandel, D. (1990) Parenting styles, drug use, and children's adjustment in families of young adults. Journal of Marriage and the Family 52 , pp. 183-196.

- 19. Kroll, B. and Taylor, A. (2003) Parental substance and child welfare Jessica Kingsley , London

- 20. Kumpfer, KL and DeMarsh, J. Griswold-Ezekoye, S., Kimpfer, KL and Bukosi, WJ (eds) (1986) Family environmental and genetic influences on children. Child and chemical abuse: Prevention and intervention pp. 49-91. Haworth Press, New York

- 21. Mayes, LC and Truman, SD Bornstein, MH (ed) (2002) Substance abuse and parenting. Handbook of parenting, 4 , pp. 329-359. 2nd, Lawrence Erlbaum Associates, Mahwah, New Jersey

- 22. McKeganey, N., Barnard, M. and Mclntosh, J. (2002) Paying the price for their parents' addiction: Meeting the needs of children of drug-using parents. Drugs: Education, prevention and policy 9 , pp. 233-246.

- 23. Meier, PS, Donmall, MC and McElduff, P. (2004) Characteristics of drug users who do or do not have care of their children. Addiction 99 , pp. 955-961.

- 24. Nunes, EV, Weisman, MM, Goldstein, RB, McAvay, G., Seracini, AM, Verdel, $\mathrm{H}$. and Wickramaratne, PJ (1998) Psychopathology in children of parents with opiate dependence and/or major depression. Journal of the American Academy of Child and Adolescent Psychiatry 37 , pp. 1142-1151.

- 25. Patterson, GR and Stouthamer-Loeber, M. (1984) The correlation of family management practices and delinquency. Child Development 55 , pp. 1299-1307.

- 26. Rounsaville, BJ, Weissman, MM, Kleber, H. and Wilber, C. (1982) Heterogeneity of psychiatric diagnosis in treated opiate addicts. Arch Gen Psychiatry 39 , pp. 161-166.

- 27. Simons, RL, Johnson, C. and Conger, RD (1994) Harsh corporal punishment versus quality of parental involvement as an explanation of adolescent maladjustment. Journal of Marriage and the Family 56 , pp. 591-607.

- 28. Stanger, C., Higgins, ST, Bickel, WK, Elk, R., Grabowski, J., Schmitz, J., Amass, L., Kirby, K. and Seracini, A. (1999) Behavioural and emotional problems among children of cocaine- and opiate-dependent parents. Journal of the American Academy of Child and Adolescent Psychiatry 38 , pp. 421-442.

- 29. Suchman, NE and Luthar, SS (2000) Maternal addiction, child maladjustment and socio-demographic risks: Implications for parenting behaviours. Addiction 95 , pp. 1417-1428.

- 30. Tarter, R., Blackson, T., Martin, C., Leber, R. and Moss, H. (1993) Characteristics and correlates of child discipline practices in substance abuse and normal families. American Journal of Addiction 2 , pp. 18-25.

- 31. Taylor, A. (1993) Women drug users: An ethnography of a female injecting community Clarendon Press, Oxford 
- 32. Velleman, R. and Templeton, L. (2003) Alcohol, drugs and the family: Results from a long-running research programme within the UK. European Addiction Research 9 , pp. 103-112.

- 33. Wasserman, DR and Levanthal, JM (1993) Maltreatment of children born to cocaine-dependent mothers. American Journal of Diseases in Children 147 , pp. 1324-1328.

- 34. Wilens, TE, Biederman, J., Kiely, K., Bredin, E. and Spencer, TJ (1995) Pilot study of behavioral and emotional disturbances in the high-risk children of parents with opioid dependence. Journal of the American Academy of Child and Adolescent Psychiatry 34 , pp. 779-785.

- 35. Wilson, JJ, Nunes, EV, Greenwald, S. and Weissman, M. (2004) Verbal and disruptive behavior disorders among children of opiate-dependent parents. American Journal on Addictions 13 , pp. 202-212. 